\title{
SISTEM PEMASARAN DAN PELUANG PENGEMBANGAN PUSAT PERDAGANGAN SAYUR-MAYUR DI KOTA PEMATANGSIANTAR
}

\author{
J ef Rudiantho Saragih \\ Dosen Fakultas Pertanian Universitas Simalungun
}

\begin{abstract}
:
The research is aim to analysis of the marketing system and prospect to develop the regional trading of vegetables in Pematangsiantar. Marketing system is determined with market place, market activity, channel of marketing, and margin share to market stakeholder. Prospect to develop of vegetables regional trading determined with efficiency of market, suitablity of location, and income of the local government. Data has analyzed by descriptive and scoring method. The research held on September to December 2003. Based on data about of the market system, this research show that vegetables market in Pematangsiantar is not efficient yet, because market location is not suitable, channel of marketing is too long, and the margin share is not proportional. The existing vegetable market in Pematangsiantar can't develop as regional trading because marketing system has not efficient yet, market location is not suitable, and local government income is zero. In general, Pematangsiantar city has several comparative advantages to develop vegetable regional trading by improvement of the market system, relocation of market place, and implementation of conducive local regulation (Perda) that aim to give win-win solution to all market stakeholder.
\end{abstract}

Keywords: vegetable market, efficiency, location, regional trading, local income

\section{Latar Belakang}

Distribusi barang dan jasa, khususnya hasil pertanian dari sentra produksi kepada konsumen akhir maslh belum mendapatkan jaminan kepastian. Kalaupun produk pertanian tersedia, umumnya tingkat kualitas, kuantitas, dan kontinuitasnya masih jauh dari kebutuhan. Pemasaran dan distribusi sayur-mayur dari sentra produksi kepada konsumen dan industri pengolah masih mengalami berbagai permasalahan, antan lain : (1) Belum mampu mengantisipasi perubahan pasar, (2) Sistem dan fasilitas distribusi masih lemah, seperti pengangkutan, pergudangan, dan asuransi. (3) Kebijakan sektor pertanian belum berpihak kepada pertanian rakyat sehingga petani berada dalam posisi tawar (bargaining position) yang lemah dalam transaksi hasil pertanian.

Diperlukan tindakan nyata untuk mengatasi permasalahan tersebut. Salah satu upaya yang dapat dilakukan adalah dibentuknya suatu infrastruktur berupa pusat pemasaran/ perdagangan sayur-mayur yang diharapkan memberi insentif produksi, harga, kualitas, dan kontinuitas hasil pertanian bagi pelaku agribisnis (produsen, perantara, dan konsumen).

Beberapa faktor yang mendukung Kota Pematangsiantar dijadikan sebagai pusat perdagangan sayur-mayur adalah : (1) daerah belakangnya (hinterland) merupakan sentra produksi pertanian dan perkebunan, (2) merupakan pusat pembangunan wilayah, (3) tersedia prasarana dan sarana transportasi darat yang lancar ke provinsi lain di Sumatera dan Pulau Jawa, (4) beberapa wilayah di Sumatera seperti Provinsi Riau, Labuhan Batu, Asahan, Tanjungbalai, Batam dan sebagian Pulau J awa, selama ini sudah "mengimpor" sayur-mayur dari Kota Pematangsiantar. Kegiatan transaksi dan transit sayur-mayur di Kota Pematangsiantar berlangsung setiap hari di lokasi sekitar 
pererempatan Jalan Sisingamangaraja dengan Jalan T. B. Simatupang1. Lokasi perempatan jalan yang demikian menyebabkan kegiatan berlangsung dalam kondisi tidak nyaman dan mengganggu kelancaran lalu lintas mengingat Jalan Sisingamangaraja adalah J alan Negara, sedangkan J alan T. B. Simatupang merupakan jalan keluar-masuk Terminal Bus Sukadame.

\section{Tujuan Penelitian}

Penelitian ini bertujuan untuk mengetahui sistem pemasaran sayur-mayur dan untuk mengkaji peluang pembentukan pusat perdagangan sayur-mayur di Kota Pematangsiantar.

\section{Metodologi Penelitian}

a. Tempat dan Waktu

Penelitian dilakukan di Kota Pematangsiantar. Secara khusus di sekitar pasar sayur J alan T.B. Simatupang, dilakukan observasi lebih Intensif. Penelitian dilaksanakan pada bulan September s.d. Desember 2003.

b. Metode Pengumpulan Data

Pengumpulan data dilakukan sebagai berikut:

(i) Studi Regulasi. Difokuskan untuk mengkaji kandungan (substansi) dari kebijakan daerah, terutama RUTRW Kota Pematangsiantar.

(ii) Observasi Lapangan. Data yang diperlukan adalah : (1) jenis sayur, (2) aktivitas angkutan barang masuk, keluar, dan lokal, (3) transaksi dan fungsi pemasaran, (4) aktivitas ikutan (derived activities) seperti bongkar muat, dan (5) penerimaan retribusi.

(iii) Resonden. Data observasi lapangan dilengkapi data wawancara dengan responden, yaitu pedagang besar, pedagang perantara, pedagang pengecer, supir truk, buruh pasar, dan penarik beca. Jumlah responden diambil dua orang setiap kategori, yang ditarik secara kebetulan (accidental sampling).

c. Metode Analisis Data

Analisis data didasarkan pada tiga aspek, yang masing-masing diberi bobot, sebagai berikut:

a. Efisiensi pasar didekati dengan beberapa indikator kinerja pasar, yang diukur dengan metode skoring. J ika kinerja baik, maka pasar dinyatakan efesien (nilai 50). Jika kinerja sangat buruk, pasar dinyatakan tidak efisien (nilai 0). Bobot untuk aspek ini ditentukan $=30 \%$.

b. Kelayakan lokasi pasar dianalisis berdasarkan RUTRW Kota. Jika sesuai diberi nilal 100 dan jika tidak sesuai diberi nilai 0 . Bobot untuk aspek ini ditentukan = $40 \%$.

c. Pendapatan daerah dari pasar dibandingkan dengan Perda Retribusi yang berlaku. J ika pendapatan sesuai atau lebih besar dari retribusi yang seharusnya diberi nilai 100 , jika tidak nilai 0 , dan jika di antaranya $(0<$ retribusi $<100)$ diberi nilai sesuai dengan persentase retribusi yang diperoleh dengan yang seharusnya. Bobot untuk aspek ini ditentukan $=30 \%$.

1 Di Kota Pematangsiantar dikenal dengan sebagai "Pasar Kelapa Sawit", karena kegiatan pasar dilakukan di bawah pohon kelapa sawit di tepi, bahu, pembatas, dan badan jalan. 
Pengambilan keputusan ditetapkan menurut jumlah skor dan bobot ketiga aspek sebagai berikut:

$$
n=\frac{\sum_{a}^{c}(\operatorname{skor} x \text { bobot })}{100}
$$

Kriteria pengambilan keputusan ditetapkan berdasarkan jumlah nilai ketiga aspek, sebagai berikut:

a. Jika $n=0-33$, aktivitas dan lokasi tidak sesuai dan perlu direlokasi.

b. Jika $n=34-55$, aktivitas dan lokasi pasar agak sesuai sehingga dapat dilanjutkan dengan pengaturan pada aspek-aspek tertentu.

c. J ika $n=67-100$, aktivitas dan lokasi pasar sesuai sehingga layak dilanjutkan dan dapat dikembangkan sebagai pusat perdagangan sayur-mayur.

\section{Lokasi Pasar}

Lokasi pasar pada umumnya berada di sepanjang J alan T.B. Simatupang (eks J alan Gotongroyong). Hasil penelitian menunjukkan bahwa secara lebih khusus, terdapat tujuh lokasi pasar yang dapat dikelompokkan menjadi:

a. Lokasi 1: sebagian J alan T.B. Simatupang sebelah kiri, mulai persimpangan J alan Rela sampai perempatan J alan Sisingamangaraja.

b. Lokasi 2: sebagian Jalan T.B. Simatupang sebelah kanan, mulai gerbang masuk Terminal Sukadame sampai perempatan J alan Sisingamangaraja.

c. Lokasi 3: sebagian J alan T.B. Simatupang sebelah kiri, mulai perempatan Jalan Sisingamangaraja sampal persimpangan J alan Bah Binomon.

d. Lokasi 4: sebagian J alan T.B. Simatupang sebelah kiri, mulai persimpangan J alan Bah Binomon sampal pemimpangan J alan Bah Biak.

e. Lokasi 5 : sebagian Jalan T. B. Simatupang sebelah kanan, mulai perempatan J alan Sisingamangaraja sampai persimpangan J alan Bah Binomon.

f. Lokasi 6 : sebagian J alan T. B. Simatupang sebelah kiri dan kanan, mulai dengan perpotongan dengan Jalan patuan Anggi sampai gerbang depan Pasar Dwikora/ Stasiun Radio CAS.

g. Lokasi 7 : Jalan Patuan Nagari sebelah kanan sekitar J alan Musyawarah, jalan M ufakat, dan pintu gerbang belakang Pasar Dwikora.

\section{Aktivitas Pasar}

a. Bongkar. Sayur yang telah dibongkar ditumpuk di pinggir (bahu) jalan hingga ke bagian badan jalan secara berkelompok menurut jenis barang dan pemilik. Barang yang masuk ke pasar diangkut oleh truck (colt-diesel dan FUSO), pick-up atau bus penumpang umum (BPU). Pembongkaran barang dilakukan oleh buruh pasar tetap yang tergabung dalam SPSI (truck dan pick-up) dan oleh kernet (BPU). Biaya pembongkaran barang untuk alat angkutan colt-diesel (Rp 50.000), pick-up (Rp 12.000), dan FUSO (Rp 70.000).

b. Muat. Pemuatan barang dilakukan oleh buruh yang tergabung dalam SPSI, tidak boleh dilakukan orang lain, termasuk pemilik barang. Biaya muat barang yang dibawa ke luar Kota Pematangsiantar, sama besamya dengan biaya bongkar.

c. Timbang. Pada umumnya, barang yang masuk sudah dikemas dalam jenis kemasan dan berat tertentu. Namun, pembeli meminta agar dilakukan penimbangan ulang, untuk pengecekan kebenarannya (verifikasi). Timbangan bak 
yang digunakan disewa dari orang yang khusus menyediakan alat timbang. J asa penimbangan adalah Rp 500 setiap kemasan, tanpa memandang beratnya.

d. Angkut (Lokal). Pengangkutan lokal yang dimaksud adalah pemindahan barang dari satu tempat ke tempat lain di dalam lingkungan pasar. J enis alat pengangkutan yang digunakan adalah 'sorong' atau becak dayung (becak tidak bermesin). Besarnya biaya ini tergantung kepada ukuran kemasan dan tujuan pengankutan barang. M isalnya: dari lokasi 3 ke lokasi 1 atau lokasi 2 atau sebaliknya, dikenakan ongkos Rp 500 (kemasan goni) dan Rp 1.000 (kemasan keranjang).

e. Transaksi. Kegiatan transaksi barang dilakukan secara lansung di tempat pembongkaran barang. Barang yang sudah ditransaksikan langsung dipindahkan (menggunakan jasa angkutan lokal) pemilik baru ke tempat baru. Transaksi terhadap satu barang di dalam pasar dapat berlangsung satu kali atau lebih. Di antara Pedagang Perantara, bisa terjadi transaksi lagi bila terdapat kesepakatan harga, dengan margin Rp 200 sampai Rp 500 per kg.

f. Eceran. Sayuran yang dijual oleh Pedagang Pengecer adalah yang diperoleh dari Pedagang Perantara. Sebagian pengecer membayar tunai, dan sebagian lagi membayar sore hari atau setelah barang terjual. Margin di tingkat pedagang pengecer tergantung jenis barang, biasanya sekitar Rp 500 sampal Rp 1.000 per kg. Pasar eceran pada umumnya berada di luar kawasan pasar, yaitu Pusat Pasar Horas dan Pasar Dwikora. Mulai pukul 05.00 berlangsung pula pasar eceran di Lokasi 7.

\section{Efisiensi Pasar}

Data dan informasi yang diperoleh dari hasil observasi dan wawancara menyangkut kinerja pasar dirangkum dalam Tabel 1.

Tabel 1. Indikator Kinerja Pasar

\begin{tabular}{llcccccccc}
\hline \multirow{2}{*}{ No. } & \multicolumn{2}{c}{ Indikator } & \multicolumn{2}{c}{ Baik (skor=5) } & \multicolumn{2}{c}{ Sedang (skor=3) } & \multicolumn{2}{c}{ Buruk (skor=1) } & \multicolumn{2}{c}{ J umlah } \\
\cline { 2 - 9 } & & $\mathrm{n}$ & skor & $\mathrm{n}$ & skor & $\mathrm{n}$ & skor & $\mathrm{n}$ & skor \\
\hline 1 & Free entry and exit & 2 & 10 & 5 & 15 & 3 & 3 & 10 & 28 \\
2 & Jumlah rantai pemasaran & 3 & 15 & 4 & 12 & 3 & 3 & 10 & 30 \\
3 & Distribusi margin & 1 & 5 & 5 & 15 & 4 & 4 & 10 & 24 \\
4 & Penerapan fungsi & 0 & 0 & 7 & 21 & 3 & 3 & 10 & 24 \\
& pemasaran & & & & & & & & \\
5 & Informasi pasar & 1 & 5 & 4 & 12 & 5 & 5 & 10 & 22 \\
& Jumlah & 7 & 35 & 26 & 78 & 17 & 17 & 10 & 120 \\
\hline
\end{tabular}

Berdasarkan jumlah skor pada Tabel 1, disusun tiga kategori kinerja pasar : buruk (skor 10-23), sedang (23-37), dan baik (38-50). Semua indikator pasar, termasuk kategori sedang, kecuall informasi pasar (kategori buruk). Secara keseluruhan, indikator pemasaran di pasar sayur J alan T.B. Simatupang adalah 120/ $5=24$ (kategori sedang).

Berdasarkan uraian di atas, kegiatan pasar yang berlaku di pasar menunjukkan sistem pemasaran yang tidak efisien. Kondisi tidak efisien ini dapat dijelaskan sebagai berikut: 
1. Rantai pemasaran. Berdasarkan pengamatan dan wawancara dengan pedagang dapat diketahui beberapa model rantai pemasaran sayur-mayur, mulai dari pasar J alan T.B. Simatupang sampai konsumen, yaitu : ${ }^{2}$
a. $\mathrm{PB} \rightarrow \mathrm{PP}-1 \rightarrow \mathrm{PP}-2 \rightarrow \mathrm{PELK} \rightarrow \mathrm{KL}$
b. $\mathrm{PB} \rightarrow \mathrm{PP}-2 \rightarrow \mathrm{PELK} \rightarrow \mathrm{KL}$
c. $\mathrm{PB} \rightarrow \mathrm{PP}-1 / \mathrm{PP}-2 \rightarrow \mathrm{PEK} \rightarrow \mathrm{KD}$
d. $\mathrm{PB} \rightarrow \mathrm{PP}-1 \rightarrow \mathrm{PEK} \rightarrow \mathrm{PEW} \rightarrow \mathrm{KD}$

Model rantai penrasaran tersebut cenderung mengakibatkan pasar sayur di Kota Pematangsiantar menjadi tidak efisien. Inefisiensi terjadi karena panjangnya rantai pemasaran sebelum sampai ke konsumen, terutama karena ada dua pedagang perantara, dan ada PEK di dalam kawasan (Lokasi 7).

2. Perlakuan Fungsi Pemasaran. Fungsi pemasaran adalah kegiatan yang dilakukan dalam rangka pelaksanaan pemasaran barang mulai dari produsen kepada konsumen. Pengenaan fungsi pemasaran akan meningkatkan nilai tambah suatu barang. Fungsi pemasaran oleh pedagang dapat dilihat pada Tabel 2.

Tabel 2. Fungsi Pemasaran di Pedagang Pasar J alan T.B. Simatupang

\begin{tabular}{clcccc}
\hline No & $\begin{array}{l}\text { Fungsi } \\
\text { Pemasaran }\end{array}$ & $\begin{array}{c}\text { Pedagang } \\
\text { Besar }\end{array}$ & $\begin{array}{c}\text { Pedagang } \\
\text { Perantara } 1\end{array}$ & $\begin{array}{c}\text { Pedagang } \\
\text { Perantara 2 }\end{array}$ & $\begin{array}{c}\text { Pedagang } \\
\text { Pengecer }\end{array}$ \\
\hline 1 & Pembelian & Ya & Ya & Ya & Ya \\
2 & Pengemasan & Tidak & Tidak & Ya & Ya \\
3 & Penimbangan & Ya & Tidak & Tidak & Ya \\
4 & Pengangkutan & Ya & Tidak & Ya & Ya \\
5 & Penyimpanan & Ya & Tidak & Ya & Ya \\
6 & Risiko & Ya & Tidak & Ya & Ya \\
7 & Penjualan & Ya & Ya & Ya & Ya \\
\hline
\end{tabular}

1) Pembagian Keuntungan (Margin Share). Keuntungan (margin) adalah selisih antara harga beli dan harga jual pada masing-masing pelaku pasar. Sebagai contoh, PP-1 membeli cabai seharga Rp 8.000 per kg, menjual ke PP-2 seharga Rp 8.500 sampai Rp 8.700 per kg. Fungsi pemasaran yang dilakukan adalah (hanya) membeli, memberi tanda (menulis nama dengan spidol) dan menjual kembali di dalam lokasi pasar. Pedagang tersebut memperoleh margin sebesar Rp 500 sampai Rp 700. Sementara PP-2 menanggung biaya kemasan dan pengangkutan. Dengan demikian, keuntungan PP-1 tidak wajar atau tidak sesuai dibandingkan dengan fungsi pemasaran dan biaya yang dikeluarkan. $\mathrm{Hal}$ ini menyebabkan baiay pemasaran menjadi semakin besar dan pembagian keuntungan di antara pelaku pasar tidak proporsional.

2) Informasi Pasar. Pasar sayur tidak berfungsi sebagai sumber informasi pemasaran, baik informasi harga maupun informasi barang (penawaran dan permintaan). Harga yang berlaku di pasar tersebut tidak menjadi acuan untuk memperkirakan harga barang hari berikutnya. Ada beberapa alasan: (a) sering terjadi tindakan spekulatif untuk mengacaukan pasokan barang, dan (b) untuk beberapa jenis barang tertentu, banyak pasokan barang berasal dari luar provinsi dan waktunya yang tidak teratur.

\footnotetext{
$2 \mathrm{~PB}=$ pedagang besar, $\mathrm{PP}-1=$ pedagang perantara $1, \mathrm{PP}-2=$ pedagang perantara $2, \mathrm{PELK}=$ pedagang pengecer luar kota, $\mathrm{PEK}=$ pedagang pengecer dalam kota, $\mathrm{PEW}=$ pedagang pengecer warung (dalam kota), $\mathrm{KL}=$ konsumen luar kota, $\mathrm{KD}=$ konsumen dalam kota.
} 


\section{Pemanfaatan Ruang}

Pola penggunaan lahan di Kota Pernatangsiantar saat ini cenderung bersifat konsentrik, artinya kegiatan perekonomian memusat di pusat kota. Oleh sebab itu, RUTRW Kota mengarahkan pengembangan, sebagai berikut: "memantapkan kota yang berperan sebagai pusat pelayanan utama kabupaten dan berfungsi sebagai pusat pelayanan regional. Salah satu fungsi penting pusat regional adalah sebagai pusat koleksi dan distribusi barang dan jasa di dalam wilayah kota, juga dalam hubungannya dengan wilayah lain".

Pasar J alan T.B. Simatupang menggunakan jalan arteri primer (jalan negara) dan jalan distribusi primer kota. Kegiatan pasar mengganggu fungsi jalan. Saat bedangsungnya kegiatan pasar, Jalan T.B. Simatupang praktis tidak dapat berfungsi. Indikator penilaian dalam aspek pemanfaatan ruang dirangkum dalam Tabel 3. Beradasrkan Tabel 3, skor rata-rata dari lima indikator adalah 30 (katagori tidak sesuai). Lokasi dan kegiatan pasar J alan T.B. Simatupang tidak sesuai dengan arahan Revisi RUTRW Kota Pematangsiantar Tahun 2002-2011.

Tabel 3. Skoring Indikator Pemanfaatan Ruang dan Fungsional Kawasan Pasar

\begin{tabular}{|c|c|c|c|}
\hline No. & Indikator & Keadaan & Skor \\
\hline 1 & Lokasi & Tidak sesuai, karena menggunakan jalan arteri. & 0 \\
\hline 2 & Waktu & $\begin{array}{l}\text { Singkat (empat jam) dan terjadi malam hari, } \\
\text { banyak barang menumpuk pada pagi hari. }\end{array}$ & 25 \\
\hline 3 & $\begin{array}{l}\text { Kegiatan ikutan } \\
\text { (derived activities) }\end{array}$ & $\begin{array}{l}\text { Siang hari, jalan digunakan untuk parkir dan } \\
\text { reparasi bus, namun tidak berhubungan langsung } \\
\text { dengan kegiatan pasar. }\end{array}$ & 50 \\
\hline 4 & $\begin{array}{l}\text { Penyebaran } \\
\text { kegiatan }\end{array}$ & $\begin{array}{l}\text { Ada penumpukan aktivitas di sekitar lokasi pasar, } \\
\text { secara akumulatif mengakibatkan kemacetan lalu } \\
\text { lintas, aktivitas pasar tidak berpengaruh dominan. }\end{array}$ & 50 \\
\hline 5 & $\begin{array}{l}\text { Hubungan fung- } \\
\text { sional dengan } \\
\text { daerah belakang }\end{array}$ & $\begin{array}{l}\text { Terdapat pasar eceran pada pagi hari, yang } \\
\text { seharusnya menjadi kegiatan daerah belakang, } \\
\text { sehingga cenderung bersifat parasit. }\end{array}$ & 25 \\
\hline & J umlah & & 150 \\
\hline & Rata-rata & & 30 \\
\hline
\end{tabular}

\section{Kontribusi dalam PAD}

Pungutan (retribusi?) yang dikenakan kepada alat angkutan barang dirangkum dalam Tabel 4.

Tabel 4. Pungutan dari Kendaraan Pengangkut Barang (per bulan)

\begin{tabular}{lccr}
\hline J enis & J umlah & Pungutan (Rp) & J umlah (Rp) \\
\hline Truk masuk & 728 & $8.000+8.000$ & 11.648 .000 \\
Truk keluar & 376 & $8.000+8.000$ & 6.016 .000 \\
Pick-up masuk & 162 & $4.000+4.000$ & 1.296 .000 \\
Pick-up keluar & 188 & $4.000+4.000$ & 1.504 .000 \\
Pedagang & 3.906 & 2.000 & 7.812 .000 \\
Eceran & Data tidak tersedia & 500 & \\
J umlah & & & 28.276 .000 \\
\hline
\end{tabular}


Dari dua jenis pungutan tersebut, Pemerintah kota (seharusnya) dapat menerima retribusi sebesar Rp 28.276.000 per bulan. J ika diperkirakan upah pungut sebesar 10\%, maka penerimaan PAD dari Pasar Kelapa Sawit adalah Rp 25.448 .000 per bulan. Akan tetapi, informasi dari Dinas Pendapatan bahwa PAD yang diperoleh dari pasar tersebut tidak ada (nihil). Berdasarkan hal ini maka diberi skor $=0$.

\section{Kelayakan Pasar}

Kelayakan lokasi dan kegiatan Pasar Kelapa Sawit untuk dikembangkan lebih lanjut sebagai pusat perdagangan sayur, diringkas dalam Tabel 5.

Tabel 5. Kelayakan Lokasi dan Aktivitas "Pasar Kelapa Sawit" sebagai Pusat Perdagangan Sayur-Mayur

\begin{tabular}{clccc}
\hline No. & \multicolumn{1}{c}{ Aspek } & Skor (S) & Bobot (B) & S x B \\
\hline 1 & Kegiatan pasar & 24 & 30 & 720 \\
2 & Pemanfaatan ruang & 30 & 40 & 1.200 \\
3 & Kontribusi ke PAD & 0 & 30 & 0 \\
& Jumlah & & & 1.920 \\
& Nilai Akhir & & 19,2 \\
\hline
\end{tabular}

\section{Kesimpulan}

a. Kinerja "Pasar Kelapa Sawit" tidak efisien, karena tidak melakukan fungsi-fungsi pemasaran yang menambah nilai tambah barang, pembagian keuntungan (margin) tidak proporsional dan mengarah ke pasar oligopoli/ oligopsoni.

b. Lokasi pasar ditinjau dari aspek pemanfaatan ruang tidak sesuai dengan RUTRW Kota Pematangsiantar.

c. Kontribusi pasar terhadap penerimaan PAD Kota Pemabngsiantar tidak ada (nihil).

d. Lokasi dan kegiatan "Pasar Kelapa Sawit" tidak sesuai (tidak layak) untuk dikembangkan lebih lanjut sebagai lokasi pusat perdagangan sayur-mayur, sehingga harus direlokasi.

\section{Rujukan}

Anonimus, 2002. Penyusunan Sistem Manajemen Pengelolaan Pusat Distribusl Regional, di

Sumatera Utara, Ditjen Perdagangan Dalam Negeri, Departemen Perindustrian dan Perdagangan RI dan PT. DanasPoe \& Co.

Branson, R.E. and D.G. Norvel, 1983. Intoduction to Agricultural Marketing, McGraw-Hill Book Company.

Dahl, D.C., 1977. M arket and Price Analysis : The Agricultural Industries, M cGraw Hill, Inc.

Pemerintah Koh Pemabngslantar, 2001. Revisi Rencana Tata Ruang Wilayah Kota Pematargsiantar Tahun 2002-2011 (Laporan Akhir).

Pemerintah Kota Pematangsiantar, 2001. Revisi Rencana Umum Tata Ruang Wilayah (RUTRW) Kota Pemabngsiantar Tahun 2002-2011 (Laporan Fakta dan Analisis).

Rhodes, V.J ., 1983. The Agricultural Marketing System, J ohn Wiley and Sons.

Saragih, Bungaran, 2002. Agribisnis, Paradigma Baru Pembangunan Ekonomi Berbasis Pertanian, Yayasan M ulia Persada Indonesia dan PT. Surveyor Indonesia.

Tomek, W.G. and K.L. Robinson, 1990. Agricultural Product Price, Cornell University Press. 